BMJ Open

Sport \&

Exercise

Medicine

\title{
Effectiveness of a standardised exercise programme for recurrent neck and low back pain: a multicentre, randomised, two-arm, parallel group trial across 34 fitness clubs in Finland
}

\author{
Jaana H Suni, Marjo Rinne, Kari Tokola, Ari Mänttäri, Tommi Vasankari
}

To cite: Suni JH, Rinne M, Tokola K, et al. Effectiveness of a standardised exercise programme for recurrent neck and low back pain: a multicentre, randomised, two-arm, parallel group trial across 34 fitness clubs in Finland. BMJ Open Sport Exerc Med 2017;3:e000233. doi:10.1136/bmjsem-2017000233

- Additional material is published online only. To view please visit the journal online (http://dx.doi.org/ 10.1136/bmjsem-2017000233).

Accepted 26 May 2017

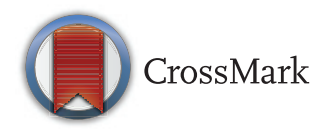

UKK Institute for Health Promotion Research, Tampere, Finland

Correspondence to Dr Jaana H Suni, UKK Institute for Health Promotion Research, Box 30 , Tampere, PL 30, 33501, Finland ; jaana.h.suni@uta.fi
ABSTRACT
Background Neck and low back pain (LBP) are common in office workers. Exercise trials to reduce neck and LBP conducted in sport sector are lacking. We investigated the effectiveness of the standardised Fustra20Neck\&Back exercise program for reducing pain and increasing fitness in office workers with recurrent non-specific neck and/or LBP.

Method Volunteers were recruited through newspaper and Facebook. The design is a multi-centre randomised, two-arm, parallel group trial across 34 fitness clubs in Finland. Eligibility was determined by structured telephone interview. Instructors were specially educated professionals. Neuromuscular exercise was individually guided twice weekly for 10 weeks. Webropol survey, and objective measurements of fitness, physical activity, and sedentary behavior were conducted at baseline, and at 3 and 12 months. Mean differences between study groups (Exercise vs Control) were analysed using a general linear mixed model according to the intention-to-treat principle. Results At least moderate intensity pain $(\geq 40 \mathrm{~mm})$ in both the neck and back was detected in $44 \%$ of participants at baseline. Exercise compliance was excellent: 92\% participated 15-20 times out of 20 possible. Intensity and frequency of neck pain, and strain in neck/shoulders decreased significantly in the Exercise group compared with the Control group. No differences in LBP and strain were detected. Neck/ shoulder and trunk flexibility improved, as did quality of life in terms of pain and physical functioning.

Conclusions The Fustra20Neck\&Back exercise program was effective for reducing neck/shoulder pain and strain, but not LBP. Evidence-based exercise programs of sports clubs have potential to prevent persistent, disabling musculoskeletal problems.

\section{INTRODUCTION}

\section{Background}

Office work is a sedentary work and may require sitting for long hours at a computer, working in awkward positions or performing repetitive manual tasks. ${ }^{1}$ Neck

\section{Summary box}

High compliance to exercise and lack of adverse effects support the use of exercise concepts such as Fustra in sport/fitness clubs.

- The Fustra concept was effective in reducing neck pain, but there is need to improve the exercises for low back pain.

- Workplaces and insurance companies might have an interest to financially support private sports sector in providing evidence-based exercise programmes to their employees.

pain and low back pain (LBP) are significant health problems in office workers, with neck pain being most common among all office workers. $^{2}{ }^{3}$ Development of chronic pain is common, ${ }^{4}$ and nearly one-third of patients with LBP do not completely recover within 12 months after the onset of pain. ${ }^{5}$ Both neck pain and LBP cause personal suffering, disability and impaired quality of work and life in general, ${ }^{6}$ placing a great socioeconomic burden on patients and society. $^{78}$

In office workers, several individual risk factors, including older age, female sex, high body mass index, lack of physical exercise, smoking, alcohol consumption and previous symptoms, are associated with neck pain. ${ }^{9}$ In addition, women and men with sickness absences due to musculoskeletal diagnoses have an increased risk of premature death, ${ }^{10}{ }^{11}$ which is attributed to physical inactivity-related non-communicable diseases (ie, cardiometabolic diseases and cancer). ${ }^{12} 13$

Exercise is one of the most commonly applied treatment choices for non-specific neck pain and LBP, but evidence regarding its effectiveness in non-specific recurrent 
patient groups is scarce, especially for those with neck pain. The most recent systematic review ${ }^{14}$ did not include findings on patients with recurrent neck pain and reported no high-quality evidence for the effectiveness of exercise for chronic neck pain. Strengthening and endurance exercises for neck/shoulder problems may be beneficial for reducing pain and improving function. ${ }^{14}$ Post-treatment exercise can reduce the recurrence of LBP, but the details of an effective exercise programme have not been specified. ${ }^{15}$ Although motor control exercises are reported to decrease the risk of recurrence at 1 year, the quality of the evidence is very low. ${ }^{16}$

\section{Objectives}

The aim of this study was to examine the effectiveness of a standardised exercise programme for reducing pain and improving fitness in office workers with recurrent non-specific neck pain and/or LBP in 34 commercial fitness clubs located in different parts of Finland. We also evaluated the effects on local musculoskeletal strain, fear avoidance beliefs, health-related quality of life and work ability. The hypothesis was that the Fustra20Neck\&Back neuromuscular exercise programme will improve the control of posture and movement, neck/shoulder and trunk flexibility, trunk muscular endurance, and leg strength, and thus decrease pain intensity by $30 \%$, compared with the non-exercise group.

\section{METHODS}

\section{Study design, settings and participants}

The study design was a multicentre, randomised, twoarm, parallel group trial where the individuals were randomised within 34 commercial fitness clubs (clusters) around Finland that provide standardised Fustra20Neck\&Back exercise programmes and agreed to take part in the study. Recruitment of study participants began with an advertisement in a nationally distributed newspaper in Finland, and volunteers contacted the UKK Institute, Tampere, Finland, by phone or email. Websites (Facebook) of both the UKK Institute and local fitness clubs were used to reach more people.

A structured telephone interview was conducted by experienced research nurses of UKK Institute to screen the eligibility of the participants. Based on these, two senior researchers (JHS, MR) of UKK Institute made the final selection of participants. The inclusion and exclusion criteria for eligibility are presented in box 1 .

\section{Intervention}

Exercise instructors were professionals (physiotherapists, or persons with a bachelor's degree in sports studies) with special training in the Fustra20Neck\&Back programme, which is an individually guided, progressive standardised neuromuscular exercise programme. The exercise dose was twice a week for 10 weeks (ie, 20 sessions). Each exercise session lasted 1 hour, and comprised 10 min aerobic warm-up with a cross trainer, 10 functional flexibility exercises (see online supplementary file 1) 4 strength and 5 core exercises (see online supplementary file 2), and a $10 \mathrm{~min}$ cool down, including instructor-assisted stretching. Participants were encouraged to continue exercising at home according to the plan provided by their personal instructor after the 10-week training period. The main aims and training principles of the Fustra20Neck\&Back are presented in box 2 .

The exercise instructors kept a diary for each participant regarding compliance and amount of each exercise during the 20 sessions. The participants were allowed to keep the training equipment (stick and foam block) for home exercise. Participants allocated to the control group were asked to continue their usual physical activity and exercise habits. After the final measurements at 12 months, controls were given the opportunity to participate in the Fustra20Nec\&Back exercise programme five times and also received the training equipment.

\section{Measurements and procedures}

The study measurements, described in table 1, were conducted at baseline, and at the 3-month and 12month follow-up. The main outcome measure was intensity of pain measured with Visual Analogue Scale $(\mathrm{VAS})^{23}$ for both the neck and low back. Questionnaire data were collected by the UKK Institute in an electronic form by sending the participants an email (and two later notices if needed) with a personal link to access the online survey tool Webropol. The pretesting health screening ${ }^{24}$ and fitness testing were conducted at the local clubs by Fustra professionals who were not instructing the interventions. The screeners received a text message from the UKK Institute's research secretary (TI) with the names and phone numbers of the participants to be tested, and then made appointments for each individual. New text messages were sent before the measurements at 3 and 12 months to remind them to make new appointments. All data gathered at the fitness clubs (including copies of the exercise diary) were mailed to the research secretary, who later saved it in an electronic form using only the identification codes of the study participants. The UKK Institute sent feedback to each participant of both study groups regarding the individual fitness test results, physical activity and sedentary behaviour after the 3-month and 12 month follow-up measurements.

Physical activity, standing still and sedentary behaviour (lying, sitting) were measured objectively by accelerometers and analysed with methods ${ }^{25} 26$ developed by the UKK Institute. In standardised conditions, standing can be separated from sitting or lying with $100 \%$ accuracy, and sitting from lying with $95 \%$ accuracy. ${ }^{27}$ The research secretary mailed the 
Box 1 Inclusion and exclusion criteria for study eligibility

\section{INCLUSION CRITERIA}

- Sedentary office worker, sitting at least 6 hours/day

- Women or men, 30-50 years of age

- Pain in the neck or/and lower back of at least moderate intensity (ie, $\geq 3$ in a Numeric Rating Scale from 0 to 10$)^{17}$ in the past 4 weeks

- At least two episodes of pain (neck or/and low back) in the past year

\section{EXCLUSION CRITERIA}

- Chronic neck or/and low back pain defined as continuous pain over 12 months

- Serious former injury in the neck or low back (fracture, surgery, whiplash, protruded disc)

- Current engagement in neuromuscular exercise at least three times a week

- Current engagement in competitive sports

- Pregnant or recently had a baby (<6 months)

Box 2 Aims and training principles of the Fustra20Neck\&Back exercise programme

\section{THE MAIN AIMS ARE TO:}

- improve body posture

- enhance movement control of shoulder-neck, lumbar and pelvic areas

- enhance stability of shoulder-neck, lumbar and pelvic areas

- increase flexibility of neck/shoulder area

- increase range of motion of thoracic spine with main emphasis on rotation

- increase muscular strength and/or endurance of upper-body, trunk and lower extremities

\section{THE MAIN PRINCIPLES OF TRAINING ARE:}

- use of functional exercises, that is, gross movement of the whole body kinetic chain

- applying the following principles of body alignment to each exercise when appropriate:

- standing feet forward and apart using a light foam 'block' $(23 \mathrm{~cm} \times 15 \mathrm{~cm} \times 8 \mathrm{~cm})$ between the feet with weight distributed equally on both feet ${ }^{18}$

neutral alignment of hips, knees and ankles, that is, avoiding excessive hip adduction or knee valgus ${ }^{18}$

no pelvic tilt forward, backward or sideways, that is, neutral pelvic posture ${ }^{18} 19$

- maintaining neutral posture (ie, zone) in cervical ${ }^{20}$ and lumbar ${ }^{21}$ spine

- avoiding forward head and rounded shoulder posture ${ }^{22}$

applying a specific breathing technique to each exercise (see instructions in online supplementary files 1 and 2) accelerometers to the participants with instructions to place it on the right hip using a flexible belt and to wear it for seven consecutive days during waking hours, except while showering and other water activities. The accelerometers were returned by mail to the UKK Institute, where the data were analysed.

\section{Randomisation and blinding}

The individual study participants at the 34 fitness clubs (clusters) were randomised immediately after the baseline measurements into exercise or control group within each location/club (ie, individual randomisation). Randomisation of the participants was conducted by a statistician (KT) who was blinded to any participant identification information other than the study code. First Microsoft Excel (2010) was used to generate a random number for each participant with RAND() function. Second, within each fitness club (cluster) roughly 50\% of participants with the highest random number were assigned to the intervention group and 50\% with the lowest random number to the control group. The exercise leaders at each club received a text message from the UKK Institute's research secretary (TI) with the names and phone numbers of the participants in the exercise group, and then made appointments for the first exercise session.

The research secretary was the only person with access to participant identification information other than the study code. The statistician and researchers were blinded to the group allocation until the end of the statistical analysis. The professionals conducting the fitness tests at each club were blinded to the group allocation at baseline, but the participants may have revealed their group during the follow-up fitness tests. The exercise instructors and participants were aware of the group allocation.

\section{Power calculation and statistical analyses}

The original plan was to have a total of 175 participants of 30 clubs (ie, mean of 5.8 participants/club) (see ClinicalTrials.gov NTC02235207). The final power calculations were based on the actual number of fitness clubs (clusters) that were willing to participate $(n=34)$ given that they would have volunteer participants fulfilling the eligibility criteria. Power calculations were carried out using the 'cluster randomization power analysis' procedure ${ }^{28}$ in PASS 11 (Power Analysis and Sample Size, NCSS, Kaysville, Utah, USA). A sample size of 34 clusters per group (exercise, control) with an average of 2.4 individuals per group (ie, 4.8 per club, a total of 163 participants) achieves $80 \%$ power to detect a difference of $10.0 \mathrm{~mm}$ in the VAS score between the group means when the $\mathrm{SD}$ is 25.0 and the intracluster correlation is 0.03 using a one-sided t-test with a significance level of 0.05 . Due to the probable dropout at 
Table 1 Description of the main outcomes and other measurements of the study

$\begin{array}{cc}\text { Measurement item } & \text { Assesment scale } \\ \text { Musculoskeletal pain and activity limitations } & \end{array}$

\section{Musculoskeletal pain and activity limitations}

Intensity of neck/low back pain in the past month ${ }^{23}$

Frequency of neck/low back pain in the last 4 weeks ${ }^{17}$

Radiating pain: from neck to arm/lower back to leg

Activity limitations due to neck/low back pain ${ }^{17}$

Perceived local musculoskeletal strain after the work day during the past month assessed for neck, shoulder, upper back, lower back, knee and hip ${ }^{38}$

Pain-related fear avoidance beliefs ${ }^{39}$ towards physical activity

Health-related quality of life ${ }^{40}$ with Finnish reference values $^{3}$

Work Ability Index (WAI), ${ }^{41}$ Short Form

Current work ability compared with the lifetime best

Work ability in relation to physical work demands

Work ability in relation to mental work demands

Personal prognosis of work ability 2 years from now

1=hardly; 4=not sure; $7=$ =almost certainly

Physical fitness tests

Stand on one leg for static balance ${ }^{\star^{42}}$

Neck-shoulder mobility (sagittal movement)*42

Trunk side-bending for spinal flexibility ${ }^{*}$

Modified push-ups for upper-body strength and ability during to stabilise trunk ${ }^{\star^{42}}$

Static squat against the wall

6 min walk test ${ }^{43}$

Physical activity and sedentary behaviour

Questionnaire developed to evaluate the fulfilment of current physical activity recommendations for health ${ }^{44}$ regarding aerobic and muscular type of activity

Objective assessment with accelerometer for 7 days (minimum of 4 days and 10 daily hours) ${ }^{24} 25$

\section{Visual Analogue Scale: 0-100 mm}

$0=$ no pain; $1=$ now and then; $2=$ most days of week, but not daily; $3=$ daily

$0=$ no; $1=$ yes

$0=$ no; $1=y e s$

Numeric Rating Scale 0-6, with manikin illustrating the body regions: $0=$ not at all; $6=$ very much

Five standard questions with Numeric Rating Scale 0-6:

$0=$ disagree; $6=$ quite agree; total score $0-30$

RAND-36 Item Health Survey (RAND-36): score 0-100 for the eight subscores

Total sum score of WAI Short Form: 3-27

Numeric Rating Scale 0-10: $0=$ not capable at all; $10=$ best possible

1=very poor; 2=poor; 3=average; 4=good; 5=very good

\section{Score 0-60s (best of 2 trials)}

Sum score (2-6) right + left sides: 1=severe limitation; $2=$ some limitation; $3=$ no limitation

Mean of right and left side bending, $\mathrm{cm}$

Number of correctly performed push-ups $40 \mathrm{~s}$

\section{Endurance score 0-90s}

Distance walked in $15 \mathrm{~m}$ indoor track

National Institute for Health, health and well-being for residents research forms: http://www.thl.fi/attachments/ATH/ 2013A1204_4.pdf

Waist-worn accelerometer (Hookie AM 20, Traxmeet, Espoo, Finland) using digital triaxial acceleration sensor (ADXL345; Analog Devices, Norwood, Massachusetts, USA) $\pm 16 \mathrm{~g}$

*A test manual and video for fitness testing is available at http://www.ukkinstituutti.fi/en/alpha.

different study phases, the aim was to recruit 180 participants.

Descriptive results are presented as proportions or means with SD. The differences between the groups at baseline were analysed by independent sample $\mathrm{t}$ test, $\chi^{2}$ test or Mann-Whitney U test. The mean difference between the two study groups (exercise vs control) at the three measurement points was analysed by a general linear mixed model (GLMM) using the IBM SPSS V.22 statistics software. All analyses were first adjusted for age, sex, weight and height, and second for civil status, education level, smoking habit and perceived fitness. Only those confounding factors that improved the model in the second stage in the sense of Bayesian information criteria were included in the final GLMM. Continuity corrected CIs for proportions were calculated with the statistical software $\mathrm{R}^{29}$ function prob.test. All analyses were performed according to the intention-totreat principle. 


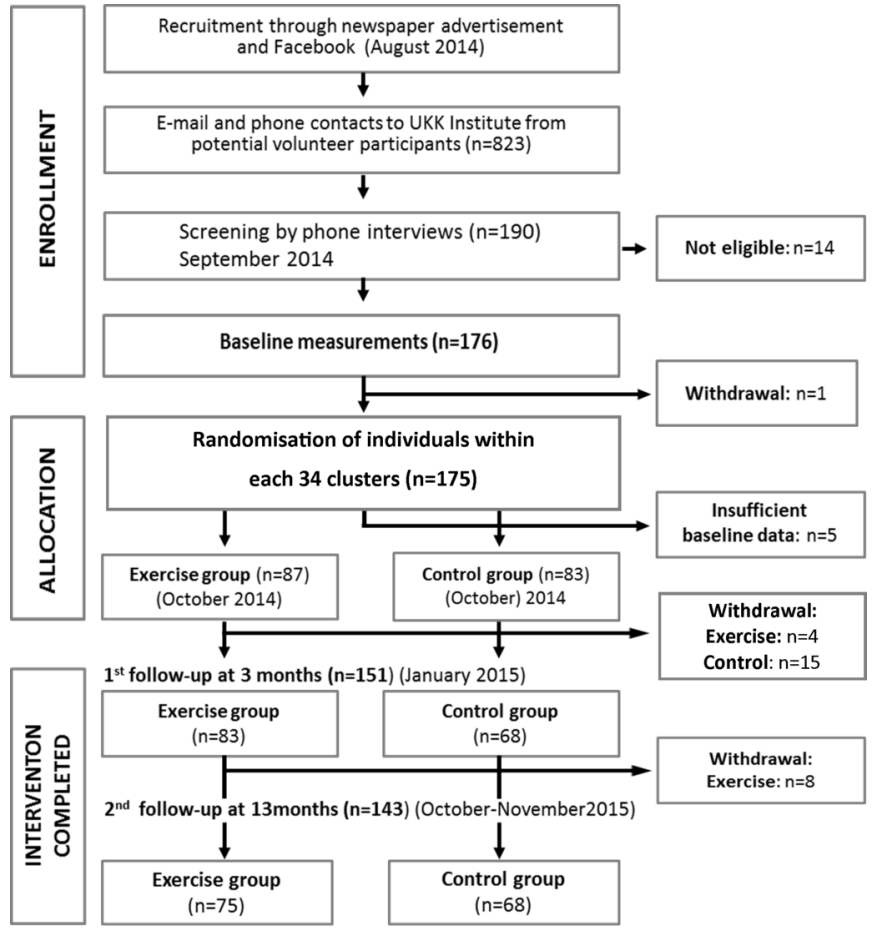

Figure 1 Study protocol and the flow of participants at different stages of the study.

\section{RESULTS}

A total of 823 people contacted the UKK Institute as interested participants; 190 were further screened, 176 were accepted for the study and 1 withdrew prior to randomisation. Five participants were excluded after baseline measurements due to insufficient data. The final exercise group included 87 participants and the control group included 83 participants. The study protocol and flow of participants at different stages of the study are presented in figure 1 .

The participant characteristics are presented in table 2. The mean age was 41 years, and the majority of the sedentary office workers were women, married/cohabitating and had a higher than average level of education. The measured daily sitting time was 8 hours and $48 \mathrm{~min}$ on workdays. There was only one statistically significant difference between the study groups: compared with control, a lower proportion of exercise group perceived their fitness to be higher or much higher than their same-age peers $(14.8 \%$ vs $27.8 \%$, $\mathrm{p}=0.04$ ). Regarding physical activity guidelines (see table 2), smaller, non-significant differences were detected for physical inactivity and meeting the muscular exercise recommendation for health. ${ }^{30}$

Descriptive results of the outcome measures at baseline are presented in table 3. There were no statistically significant differences between the study groups in any of the outcome measures.

At least moderate-intensity ('clinically meaningful') pain $(\geq 40 \mathrm{~mm})$ on the VAS score for both neck pain and low back was detected in $44 \%$ of the participants. The mean intensity and frequency of pain were higher for the neck than the low back, as was having radiating pain to the arm compared with the leg. Perceived local musculoskeletal strain after workdays was also higher in the neck and shoulders than in the back.

Severe limitations in sagittal level mobility of the neck and shoulder were reported by $56 \%$ of the men and by $39 \%$ of the women. Fear avoidance beliefs related to physical activity were low (mean 8.2/0-30), indicating that fear of pain was an unlikely reason for possible lack of physical activity. The Work Ability Index was at a fairly good level (mean 18.7/ 3-27). Reduced quality of life ${ }^{31}$ was detected for subscales of 'Pain' and 'Energy' $(<60 / 0-100)$, and 'Physical health' and physical 'Role functioning' $(<70 / 0-100)$.

\section{Compliance with neuromuscular exercise and adverse effects}

The exercise compliance was high: $67 \%(n=58)$ of the participants completed all 20 exercise sessions, $25 \%(\mathrm{n}=22)$ exercised 15-19 times, 6\% $(\mathrm{n}=5)$ 8-11 times and $2 \%(\mathrm{n}=2)$ did not show up at all. No adverse effects of training were reported during the study by either the instructors or participants. Findings on pain and musculoskeletal strain in different anatomic sites at the 3-month follow-up confirmed the latter findings. 
Table 2 Background characteristics of the participants by study group

\begin{tabular}{|c|c|c|c|c|c|}
\hline \multirow[b]{2}{*}{ Characteristics } & \multicolumn{5}{|l|}{ Study groups } \\
\hline & $\begin{array}{l}\text { Exercise } \\
(\mathrm{n}=87)\end{array}$ & $\begin{array}{l}\text { Control } \\
(n=83)\end{array}$ & $\begin{array}{l}\text { All } \\
(n=170)\end{array}$ & p Value & $\begin{array}{l}\text { Missing } \\
\text { (n) }\end{array}$ \\
\hline Age: years (mean, SD) & $40.7(6.0)$ & $41.6(5.7)$ & $41.1(5.9)$ & $0.36^{1}$ & 0 \\
\hline Sex: female & $80.5 \%$ & $78.3 \%$ & $79.4 \%$ & $0.97^{2}$ & 0 \\
\hline Civil status: married/cohabiting & $83.7 \%$ & $80.7 \%$ & $82.4 \%$ & $0.59^{2}$ & 0 \\
\hline Education: secondary school graduate & $79.3 \%$ & $81.9 \%$ & $80.6 \%$ & $0.67^{2}$ & 0 \\
\hline Professional degree: polytechnic or higher & $63.2 \%$ & $65.1 \%$ & $64.1 \%$ & $0.80^{2}$ & 0 \\
\hline Smoking: non-smoker & $80.5 \%$ & $88.0 \%$ & $84.1 \%$ & $0.18^{2}$ & 0 \\
\hline Elevated blood pressure (self-report): yes & $9.9 \%$ & $4.0 \%$ & $7.4 \%$ & $0.35^{2}$ & 8 \\
\hline Dizziness (self-report): yes & $13.6 \%$ & $13.6 \%$ & $13.6 \%$ & $1.00^{2}$ & 8 \\
\hline Use of medication (self-report): yes & $23.5 \%$ & $27.2 \%$ & $25.3 \%$ & $0.59^{2}$ & 8 \\
\hline \multicolumn{6}{|l|}{ Perceived fitness compared with same-age peers } \\
\hline Higher or much higher & $14.8 \%$ & $27.8 \%$ & $21.3 \%$ & $0.040^{2}$ & 3 \\
\hline Lower or much lower & $35.8 \%$ & $34.2 \%$ & $35.0 \%$ & $0.74^{2}$ & 10 \\
\hline $\begin{array}{l}\text { Fulfilment of physical activity (PA) guidelines, self- } \\
\text { report }\end{array}$ & & & & $0.37^{2}$ & \\
\hline Aerobic type activity* & $22.6 \%$ & $23.2 \%$ & $22.9 \%$ & & 3 \\
\hline Muscular exercise $\dagger$ & $15.5 \%$ & $25.6 \%$ & $20.6 \%$ & & 3 \\
\hline Both aerobic and muscular & $9.5 \%$ & $9.8 \%$ & $9.7 \%$ & & 3 \\
\hline Physically inactive (not meeting either guideline) & $52.4 \%$ & $41.5 \%$ & $46.9 \%$ & & 3 \\
\hline \multicolumn{6}{|l|}{ Fulfilment of PA guidelines, accelerometer } \\
\hline Aerobic type activity* & $29.4 \%$ & $26.7 \%$ & $28.6 \%$ & $0.70^{2}$ & 10 \\
\hline \multicolumn{6}{|l|}{ Other accelerometer measurements } \\
\hline $\begin{array}{l}\text { Mean daily sitting time during week days, } \\
\text { accelerometer }\end{array}$ & 8 hour 42 min & 8 hour 54 min & $\begin{array}{l}8 \text { hour } \\
48 \text { min }\end{array}$ & $0.31^{1}$ & 10 \\
\hline \multicolumn{6}{|l|}{$\begin{array}{l}\text { Proportion of mean daily recording time (minimum } \\
10 \text { hours/day) }\end{array}$} \\
\hline Sedentary behaviour (lying/sitting) & $61.7 \%$ & $62.4 \%$ & $62 \%$ & $0.59^{1}$ & 10 \\
\hline Standing & $16.2 \%$ & $16.2 \%$ & $16.2 \%$ & $0.98^{1}$ & 10 \\
\hline Light intensity physical activity (METs, $₫ 1.5-2.9$ ) & $12.9 \%$ & $12.6 \%$ & $12.7 \%$ & $0.43^{1}$ & 10 \\
\hline Moderate intensity physical activity (METs, 3.0-5.9) & $8.5 \%$ & $8.1 \%$ & $8.3 \%$ & $0.34^{1}$ & 10 \\
\hline Vigorous intensity physical activity (METs, $\geq 6.0$ ) & $0.7 \%$ & $0.7 \%$ & $0.7 \%$ & $0.40^{3}$ & 10 \\
\hline
\end{tabular}

Statistical methods: ${ }^{1}$ indenpendent samples t-test, ${ }^{2} \chi^{2}$ test, ${ }^{3}$ Mann-Whitney $U$ test.

*Adults should be active several days ( $\geq 3$ times) a week and accumulate 150 min of moderate or 75 min of vigorous-intensity physical activity (or their combination) of bouts $\geq 10$ min.

$\dagger$ Muscle strengthening activity for large muscle groups twice a week ( $\geq 20 \mathrm{~min} / \mathrm{session})$ is recommended.

$\ddagger$ METs, that is, metabolic equivalents; 1 MET equals oxygen consumption of $3.5 \mathrm{~mL} / \mathrm{min} / \mathrm{kg}$.

\section{Effectiveness of the standardised Fustra20Neck\&Back programme}

The results are presented as the mean difference with $95 \%$ CI in figures $2-4$. The decrease in pain intensity $(\mathrm{p}=0.001$, figure $2 \mathrm{~A})$ and frequency $(\mathrm{p}=0.024$, figure $2 \mathrm{C})$, and strain $(\mathrm{p}=0.002$, figure $2 \mathrm{E})$ in the neck and shoulders, in the exercise group was significantly greater compared with the control group, with the decrease in intensity of neck pain bigger than the minimal important change $(\geq 15 \mathrm{~mm}$ of the VAS score), ${ }^{27}$ with a mean reduction of $30 \mathrm{~mm}$ at 3 months and $23 \mathrm{~mm}$ at 12 months (figure 2A). Effect size (Cohen's d) of VAS score in the neck was 0.453 and 0.364 in the back. The proportion with daily/almost 
Table 3 Baseline characteristics of musculoskeletal pain and local strain, physical fitness, fear avoidance beliefs, work ability and quality of life of the study participants

\begin{tabular}{|c|c|c|c|c|}
\hline \multirow[b]{2}{*}{ Characteristics } & \multicolumn{4}{|l|}{ Study groups } \\
\hline & Exercise $(n=87)$ & Control $(n=83)$ & All $(n=170)$ & \\
\hline Intensity of pain during the past month & Mean (SD) & Mean (SD) & Mean (SD) & p Value \\
\hline Visual Analogue Scale (0-100 mm), neck pain & $52.9(24.4)$ & $51.4(26.5)$ & $52.2(25.4)$ & $0.70^{1}$ \\
\hline Visual Analogue Scale (0-100 mm), low back pain & $40.2(24.1)$ & $39.0(23.6)$ & $39.6(23.8)$ & $0.75^{1}$ \\
\hline Proportion with & $\%$ & $\%$ & $\%$ & \\
\hline pain intensity at least $40 \mathrm{~mm}$ for both neck and back & 43.7 & 43.4 & 43.5 & $0.97^{2}$ \\
\hline pain frequency of daily or almost daily pain in neck & 59.8 & 61.4 & 60.6 & $0.83^{2}$ \\
\hline pain frequency of daily or almost daily pain in back & 37.9 & 36.1 & 37.1 & $0.81^{2}$ \\
\hline radiating pain from neck to upper limb & 40.2 & 37.3 & 38.8 & $0.70^{2}$ \\
\hline radiating pain from back to knee level & 14.9 & 22.9 & 18.8 & $0.19^{2}$ \\
\hline activity limitations due to neck pain & 14.9 & 7.2 & 11.2 & $0.11^{2}$ \\
\hline activity limitations due to back pain & 9.2 & 9.6 & 9.4 & $0.92^{2}$ \\
\hline $\begin{array}{l}\text { Local musculoskeletal strain after work days during } \\
\text { past month (rating 0-6) }\end{array}$ & Mean (SD) & Mean(SD) & Mean (SD) & \\
\hline Neck & $4.2(1.3)$ & $4.0(1.5)$ & $4.1(1.4)$ & $0.22^{1}$ \\
\hline Shoulder & $4.2(1.3)$ & $4.1(1.4)$ & $4.2(1.4)$ & $0.64^{1}$ \\
\hline Upper back & $3.2(1.6)$ & $3.1(1.7)$ & $3.2(1.7)$ & $0.51^{1}$ \\
\hline Lower back & $3.3(1.7)$ & $3.2(1.6)$ & $3.2(1.6)$ & $0.68^{1}$ \\
\hline Hip & $1.4(1.5)$ & $1.4(1.4)$ & $1.4(1.5)$ & $0.74^{1}$ \\
\hline Knee & $0.7(1.1)$ & $1.1(1.4)$ & $0.9(1.3)$ & $0.10^{1}$ \\
\hline $\begin{array}{l}\text { Physical fitness }(\mathrm{W}=\text { women, } M=\text { men }) \\
\text { Static balance }(0-60 \mathrm{~s}) \mathrm{W}(0)^{\star} \\
M(1)^{\star}\end{array}$ & $\begin{array}{l}54.9(12.8) \\
51.7(17.9)\end{array}$ & $\begin{array}{l}56.3(9.9) \\
51.0(16.8)\end{array}$ & $\begin{array}{l}55.5(11.5) \\
51.3(17.19)\end{array}$ & $\begin{array}{l}0.57^{1} \\
0.981\end{array}$ \\
\hline & $\%$ & $\%$ & $\%$ & \\
\hline $\begin{array}{l}\text { Neck-shoulder mobility } W(0)^{*} \\
\left(\% \text { with severe limitation) } M(1)^{*}\right.\end{array}$ & $\begin{array}{l}40.0 \\
56.3\end{array}$ & $\begin{array}{l}37.3 \\
56.3\end{array}$ & $\begin{array}{l}38.7 \\
56.3\end{array}$ & $0.75^{2}$ \\
\hline & Mean (SD) & Mean (SD) & Mean (SD) & \\
\hline $\begin{array}{l}\text { Trunk side-bending flexibility }(\mathrm{cm}) \\
\qquad \begin{array}{l}\mathrm{W}(2)^{\star} \\
\mathrm{M}(2)^{\star}\end{array}\end{array}$ & $\begin{array}{l}18.3(13.6) \\
18.2(4.7)\end{array}$ & $18.6(4.4)$ & $\begin{array}{l}18.7(3.5) \\
18.4(4.5)\end{array}$ & $\begin{array}{l}0.25^{1} \\
0.79^{1}\end{array}$ \\
\hline $\begin{array}{l}\text { Modified push-ups (repetitions) } \\
W(5)^{\star} \\
M(1)^{\star}\end{array}$ & $6.9(4.0)$ & $10.4(4.6)$ & $10.0(3.9)$ & $\begin{array}{l}0.24^{1} \\
0.18^{1}\end{array}$ \\
\hline $\begin{array}{l}\text { Static wall squat }(0-90 \mathrm{~s}) \\
\qquad \begin{array}{l}\mathrm{W}(0)^{\star} \\
M(1)^{\star}\end{array}\end{array}$ & $83(50)$ & $87(53)$ & $85(51)$ & $\begin{array}{l}0.17^{1} \\
0.76^{1}\end{array}$ \\
\hline $\begin{array}{l}6 \text { min walk test (distance walked, } \mathrm{m} \text { ) } \\
\mathrm{W}(3)^{\star} \\
M(1)^{\star}\end{array}$ & $635(60)$ & $631(62)$ & $633(61)$ & $\begin{array}{l}0.55^{1} \\
0.39^{1}\end{array}$ \\
\hline Fear avoidance beliefs, physical activity (sum score 0-30) & $8.7(5.4)$ & $7.7(4.3)$ & $8.2(4.9)$ & $0.21^{1}$ \\
\hline Work Ability Index, Short Form (sum score 3-27) & $18.6(1.5)$ & $18.8(1.0)$ & $18.7(1.3)$ & $0.30^{1}$ \\
\hline
\end{tabular}


Table 3 Continued

\section{Characteristics}

Study groups

\begin{tabular}{lllll}
\hline Health-related quality of life, RAND-36 & & & & \\
Bodily pain (0-100) & $56.6(17.6)$ & $60.2(15)$. & $58.3(16.8)$ & $0.17^{1}$ \\
\hline Energy/Nitality (0-100) & $61.3(18.2)$ & $57.4(18.6)$ & $59.4(18.5)$ & $0.17^{1}$ \\
\hline General health perceptions (0-100) & $66.5(18.0)$ & $66.5(17.9)$ & $66.5(17.9)$ & $1.00^{1}$ \\
Role functioning, physical (0-100) & $63.2(38.3)$ & $71.1(33.9)$ & $67.1(36.3)$ & $0.16^{1}$ \\
Emotional well-being (0-100) & $74.3(14.1)$ & $73.2(15.3)$ & $73.8(14.7)$ & $0.60^{1}$ \\
\hline Role functioning, emotional (0-100) & $80.1(31.9)$ & $77.5(32.6)$ & $78.8(32.2)$ & $0.61^{1}$ \\
Social functioning (0-100) & $79.7(19.7)$ & $81.3(20.4)$ & $80.5(20.0)$ & $0.61^{1}$ \\
\hline Physical functioning (0-100) & $85.9(14.8)$ & $89.3(9.8)$ & $87.6(12.7)$ & $0.07^{1}$ \\
\hline
\end{tabular}

*The number of missing cases in each of the fitness tests is presented in parenthesis; there were no missing cases for questionnaire data. Statistical method: ${ }^{1}$ indenpendent samples t-test, ${ }^{2} \chi^{2}$ test.

daily neck pain in the exercise group was reduced $45 \%$ from baseline to 3 months and $33 \%$ from baseline to 12 months (figure 2C). The reduction of perceived work-induced local strain in the neck and shoulder (figure 2E) was $28 \%$ at 3 months and $32 \%$ at 12 months. No between-group differences were detected
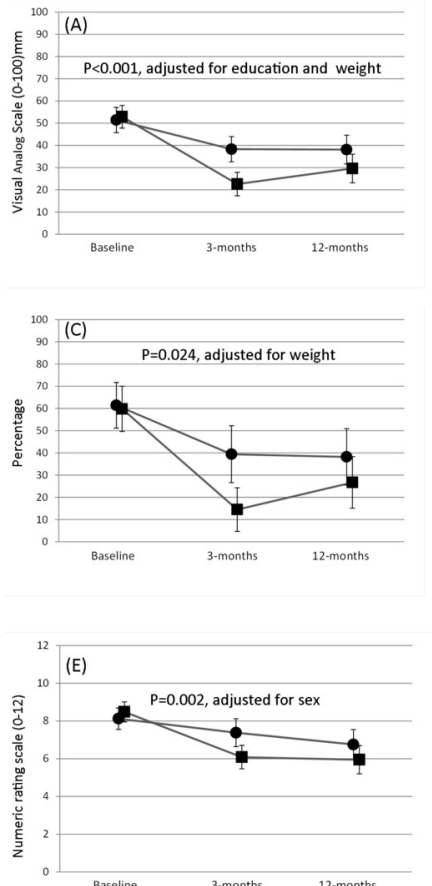

- Exercise-group; • Control-group; ns= non-significant between group difference

Number $(\mathbf{n})$ of subjects at each time point: in the intensity (figure 2B) and frequency of LBP (figure 2D) or local strain in the upper and lower back (figure 2F).

The exercise group compared with control had significantly greater improvements in neck-shoulder $(p=0.014$, figure $3 \mathrm{~A})$ and trunk side-bending flexibility
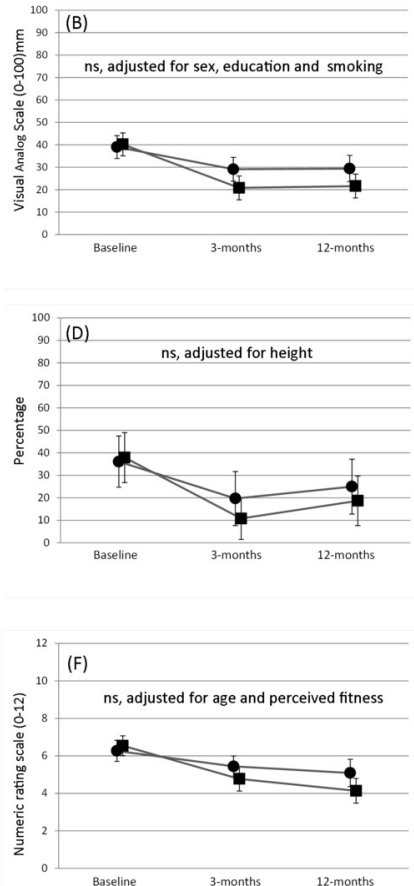

$\begin{array}{ccc}\text { Baseline } & \text { 3-months } & \text { 12-month } \\ \text { - } n=87 & n=83 & n=75 \\ n=83 & n=66 & n=68\end{array}$

Figure 2 Changes in intensity and frequency of pain and work-induced local musculoskeletal strain between baseline, 3month and 12-month follow-up. (A) Intensity of neck pain and (B) intensity of low back pain; lower number indicates positive outcome and $\geq 15 \mathrm{~mm}$ change indicates minimal important change. (C) Frequency of neck pain and (D) frequency of low back pain; proportion with daily or almost daily pain, lower number indicates positive outcome. (E) Local strain in neck and shoulders and $(F)$ local strain in upper and lower back; Numeric Rating Scale (0-6), sum score of two locations (0-12), smaller number indicates positive outcome. 

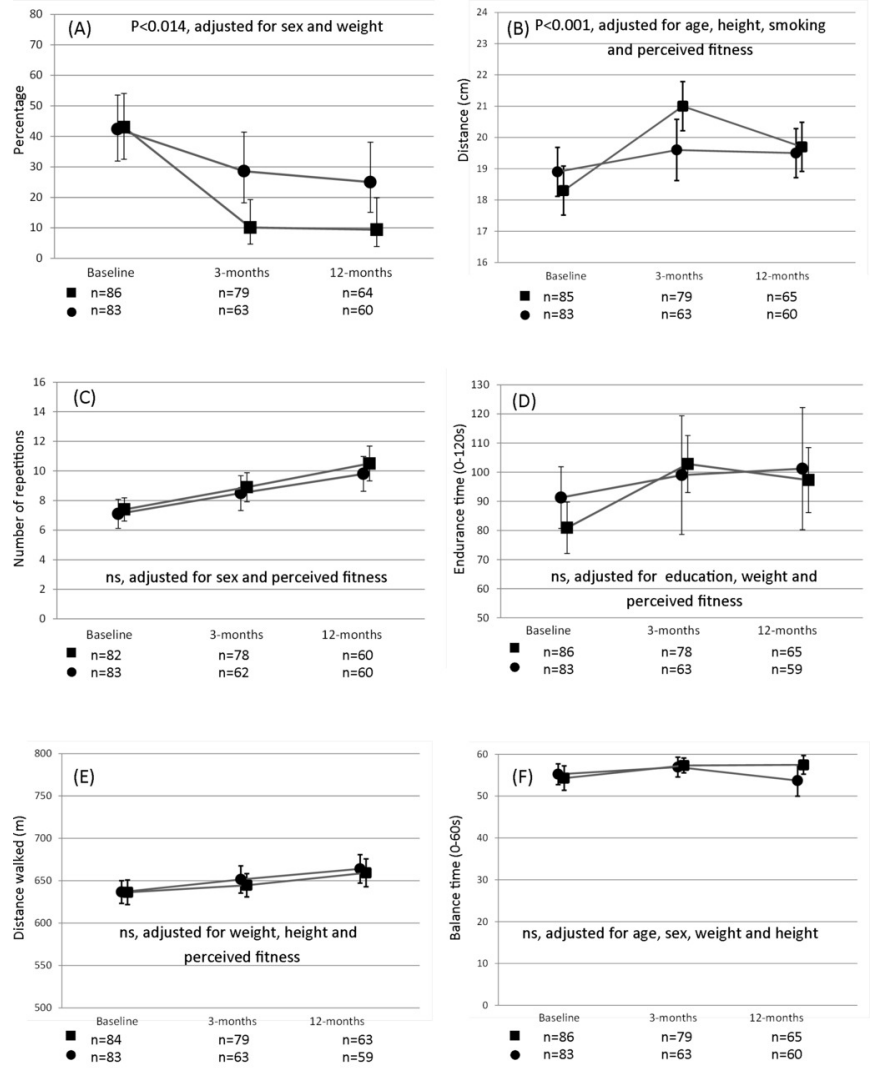

- Exercise-group; • Control-group; ns= non-significant between group difference

n=number of participant at each measurement point

Figure 3 Changes in physical fitness between baseline, 3-month and 12-month follow-up: (A) Mobility limitations in neckshoulder area; \% with severe limitations, lower number indicates positive change. (B) Flexibility in trunk side-bending; average of right and left side (cm), higher number indicates positive change. (C) Upper-body strength and trunk stability; number of modified push-ups in $40 \mathrm{~s}$, higher number indicates positive change. (D) Lower extremity endurance; endurance time in static squat position, higher number indicates positive change. (E) Cardiorespiratory fitness measured with 6 min walk test; distance walked, higher number indicates positive change. (F) Static balance in one-leg stand; time managed to stand still, higher number indicates positive change.

$(p<0.001$, figure $3 \mathrm{~B})$. The results of the other fitness tests (figure 3) of modified push-ups (figure 3C), static wall squat (figure 3D), 6 min walk test (figure $3 \mathrm{E}$ ) and static balance (figure 3F) were not significantly different between groups. The modified push-ups, wall squat and 6 min walk test all had significant positive time effects $(\mathrm{p}<0.001)$.

The changes in health-related quality of life are presented for six of the eight subscales (figure 4), excluding 'Social functioning' and emotional 'Role limitations', which both had high mean baseline values (table 1) and seemed to be not highly relevant as outcomes for an exercise intervention. Statistically significant differences in favour of the exercise group were detected in the RAND-36 subscales of 'Pain' $(\mathrm{p}=0.003$, figure $4 \mathrm{~A})$ and 'Physical functioning' $(p=0.022$, figure $4 B)$. A positive time effect was demonstrated for 'Role limitations' due to physical health ( $\mathrm{p}<0.001$, figure 4D), 'General health' $(p=0.001$, figure $4 \mathrm{C})$ and 'Energy' $(p=0.004$, figure $4 \mathrm{E})$.

\section{DISCUSSION}

The findings of the present study indicate that the standardised Fustra20Neck\&Back exercise programme is effective for reducing pain and work-induced local strain in the neck/shoulder area, but not in the lower back. In addition, exercise improved upper-body mobility and health-related quality of life in terms of perceived interference of pain and physical functioning. The positive effects seemed to be maintained during the 12-month follow-up.

Neck and LPB are the two major reasons for visiting primary healthcare providers, the proportion seeking help being much higher among those who report intense pain in both the neck and lower back compared with those with pain at either site. ${ }^{32}$ Neuromuscular exercise is the only mode of therapeutic exercise reported to be effective for relieving pain and disability of non-specific neck pain and LBP. ${ }^{14-16}$ The present study is the first to report results on the effectiveness of a standardised exercise programme for reducing neck and LBP within the private sport sector. This is of great 
importance for society because occupational and primary healthcare lack the resources required to provide large-scale exercise counselling or instructed exercise sessions.

The main reason that the Fustra20Neck\&Back reduced pain and strain in the neck and shoulders but not in the low back relate to the fact that the majority of the exercises targeted posture and movement control of the head, neck and shoulders (see online supplementary files 1 and 2), and there was a lack of functional exercises, such as the squat, ${ }^{33}$ that are aimed at improving control of the lumbar neutral zone. Different types of squat patterns are required for activities of daily living, such as sitting down and lifting, and most sporting activities. ${ }^{34}$ The Fustra20 Neck \& Back programme also lacked exercises such as the sidebridge to challenge the musculus quadratus lumborum $^{35}$ along with other key stabilising muscles of the trunk (external/internal oblique, lumbar multifidus, erector spinae, latissimus dorsi) without causing a notable increase in compressive forces acting on the lumbar spine. $^{36}$ Four-point kneeling ${ }^{37}$ would be another safe and effective exercise that requires various trunk muscle activation patterns and challenges the ability to stabilise the pelvis.

The most unique feature of the present study is the high compliance with exercise: 80 of 87 participants completed at least 15 exercise sessions, but 5 of them were lost to follow-up at 12 months $(\mathrm{n}=75)$. An important factor for high compliance might be that the instructors acted as personal trainers. The physical and psychosocial environment of sports clubs may also differ positively from that of healthcare. Third, many of the over 800 volunteers interested in participating were familiar with the trademark of Fustra beforehand and expressed positive expectations. Finally, the study participants had free access to the training, for which the normal market price was around $€ 70$ per session at the time of the study.

\section{Strengths of the study}

To our knowledge, this is one of the first studies within private sport sector utilising a standardised registered exercise concept (Fustra) to prevent chronic pain and disability in office workers with neck pain and/or LBP. To become a qualified instructor, a special 2-week
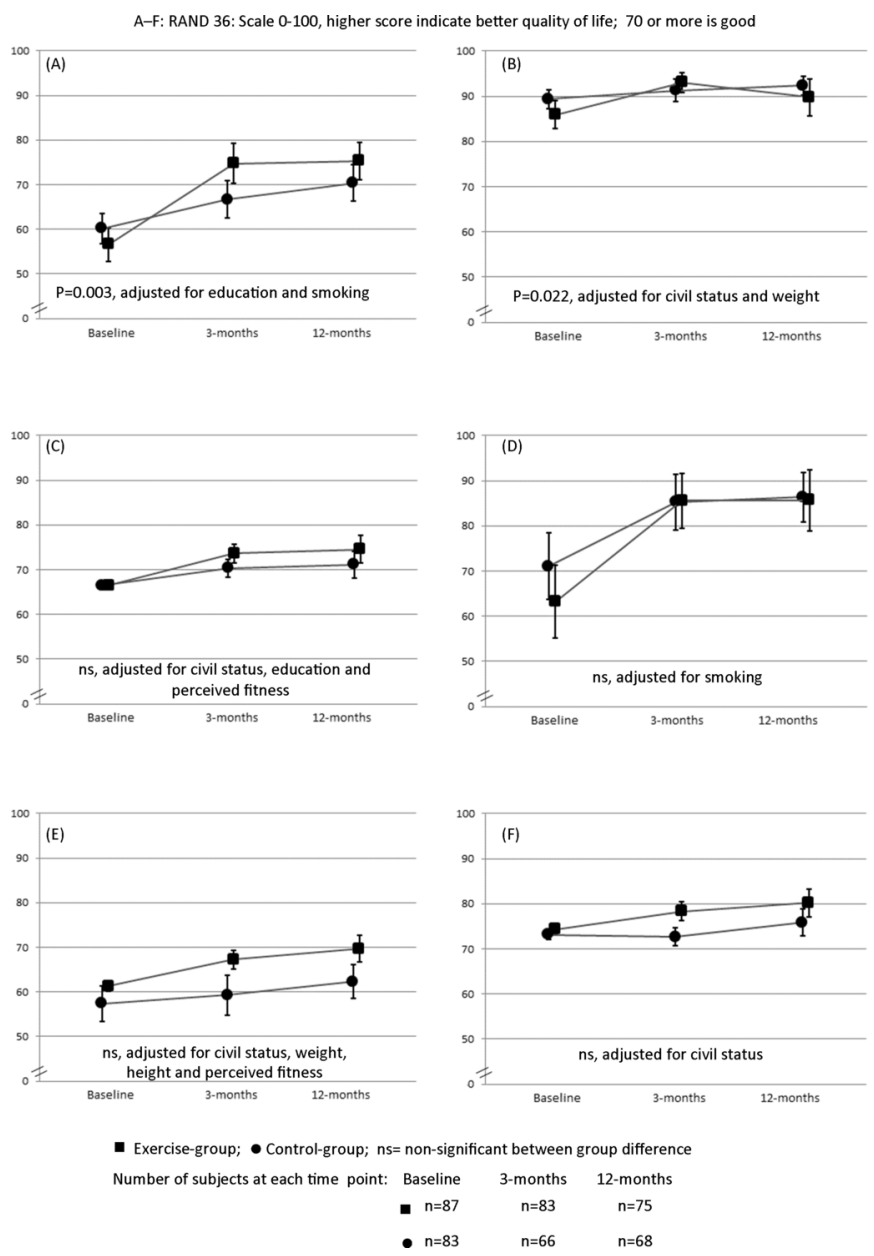

Figure 4 Changes in quality of life between baseline, 3-month and 12-month follow-up: (A) pain, (B) physical functioning, (C) general health, (D) role limitations due to physical health, $(E)$ energy and $(F)$ emotional well-being; higher number indicates positive change. 
training course, including lectures on functional anatomy, exercise physiology, nutrition and practice to instruct three different exercise programmes (including Fustra20Neck\&Back), is required. In the present study, all instructors were either physiotherapists or possessed a bachelor's degree in sports studies.

\section{Limitations of the study}

The major limitation of the study is that data on exercise compliance after the instructed 20 exercise sessions were not systematically collected during the second follow-up. All participants were provided with written home exercise instructions by their trainer, but systematic follow-up on compliance was not part of the standardised Fustra20Neck\&Back exercise programme at that time. Recently, phone apps to facilitate continuing exercise at home were launched by Fustra, including a personal diary for follow-up. Regarding the present study, it is not known whether the reduction in pain and local musculoskeletal strain at 12 months was only due to the 3-month instructed exercise training or both the instructed training and continued selftraining. A practical real-life limitation outside the study is the fairly high price of Fustra training, which certainly limits the ability of all people to participate.

\section{CONCLUSIONS}

The standardised Fustra20Neck\&Back exercise programme was effective for reducing pain and local strain in the neck/shoulder area and improving upperbody mobility, but not for reducing pain and strain in the low back. Positive findings on neck pain, high compliance to exercise and lack of adverse effects support the use of the programme in sport/fitness clubs. These findings should encourage the Fustra founders to develop the contents as suggested. In general, sport and fitness clubs outside the medical domain may offer an important means to reduce chronic musculoskeletal problems in occupational populations.

\section{DECLARATIONS}

\section{Ethics approval and consent to participate}

The study was carried out conforming to the guidelines of good scientific practice and provisions of the Declaration of Helsinki. Approval of the study protocol was provided by the Ethical Committee of Pirkanmaa Hospital District (R14030). The clinical trial registration number is NCT02235207.

Accepted participants were invited to the study by personal email message by the study secretary of the UKK Institute. The detailed announcements of the study and approval papers to be signed were included as an attachment. Each participant personally gave the signed approval document to the Fustra fitness tester at the beginning of the baseline measurement of fitness, who then mailed the approval document along with pretesting health-screening and fitness test results to the UKK Institute.

\section{Consent to publish}

The person shown in online supplementary files 1 and 2 is Jarkko Kortelainen, who is the founder of the Fustra Neck \& Back exercise programme. He provided all the material needed for files 1 and 2 to the first author, Jaana H Suni, and has accepted the contents of these additional files.

Acknowledgements The authors would like to thank the product development director, Jarkko Kortelainen, from Fustra Finland International Oy, the founder of the Fustra Neck \& Back programme, for his help in describing the exercise programprogramme and participating in discussions on the results of the effectiveness of the programprogramme. We also thank the research secretary, Tiina Inkovaara, from the UKK Institute, and the head of training division, Tiina Ruotsalainen, from Fustra Finland International Oy, for their successful cooperation in advising the Fustra fitness testers and Fustra instructors on study details, as well as answering the numerous questions of the participants during the different stages of the study.

Contributors All authors read and approved the final manuscript. JHS, MR, $\mathrm{AM}$ and TV were responsible for the study design, selection of the research methods and interpretation of the study results. KT is a statistician and was responsible for power calculations, randomisation, selecting statistical analyses and conducting data analysis. KT is currently finalising his thesis on cluster-randomised study designs.

Funding Fustra Finland International Oy paid money to the UKK Institute to cover part of the working hours of the research secretary (TI) during the study and the four study nurses involved with recruitment, mailing the accelerometers to participants and saving the raw accelerometer data for further analysis. None of the research group members of the UKK Institute received money or other benefits from Fustra Finland International $0 y$ at any point during the study.

Competing interests None declared.

Patient consent Obtained.

Ethics approval Ethical Committee of Pirkanmaa Hospital district, Finland (R14030).

Provenance and peer review Not commissioned; externally peer reviewed.

Data sharing statement No employees of Fustra Finland International Oy had access to the research data set at any time during the study.

Open Access This is an Open Access article distributed in accordance with the Creative Commons Attribution Non Commercial (CC BY-NC 4.0) license, which permits others to distribute, remix, adapt, build upon this work noncommercially, and license their derivative works on different terms, provided the original work is properly cited and the use is non-commercial. See: http:// creativecommons.org/licenses/by-nc/4.0/

(c) Article author(s) (or their employer(s) unless otherwise stated in the text of the article) 2017. All rights reserved. No commercial use is permitted unless otherwise expressly granted.

\section{REFERENCES}

1. Paksaichol A, Janwantanakul P, Purepong N, et al. Office workers' risk factors for the development of non-specific neck pain: a systematic review of prospective cohort studies. Occup Environ Med 2012;69:610-8.

2. Janwantanakul $P$, Pensri $P$, Jiamjarasrangsri $V$, et al. Prevalence of self-reported musculoskeletal symptoms among office workers. Occup Med 2008;58:436-8.

3. Ayanniyi O, Ukpai BO, Adeniyi AF. Differences in prevalence of selfreported musculoskeletal symptoms among computer and noncomputer users in a nigerian population: a cross-sectional study. BMC Musculoskelet Disord 2010;11:177. 
4. Sihawong R, Sitthipornvorakul E, Paksaichol A, et al. Predictors for chronic neck and low back pain in office workers: a 1-year prospective cohort study. J Occup Health 2016;58:16-24.

5. Henschke N, Maher CG, Refshauge KM, et al. Prognosis in patients with recent onset low back pain in australian primary care: inception cohort study. BMJ 2008;337:a171.

6. Vos $T$, Flaxman $A D$, Naghavi $M$, et al. Years lived with disability (YLDs) for 1160 sequelae of 289 diseases and injuries 1990-2010: a systematic analysis for the global burden of disease study 2010 . Lancet 2012;380:2163-96.

7. van den Heuvel SG, ljmker S, Blatter BM, et al. Loss of productivity due to neck/shoulder symptoms and hand/arm symptoms: results from the PROMO-study. J Occup Rehabil 2007:17:370-82.

8. Global Burden of Disease Study 2013 Collaborators. Global, regional, and national incidence, prevalence, and years lived with disability for 301 acute and chronic diseases and injuries in 188 countries, 1990-2013: a systematic analysis for the global burden of disease study 2013. Lancet 2015;386:743-800.

9. Cagnie B, Danneels L, Van Tiggelen D, et al. Individual and work related risk factors for neck pain among office workers: a cross sectional study. Eur Spine J 2007;16:679-86.

10. Jansson C, Mittendorfer-Rutz E, Alexanderson K. Sickness absence because of musculoskeletal diagnoses and risk of all-cause and cause-specific mortality: a nationwide swedish cohort study. Pain 2012;153:998-1005

11. Haugen IK, Ramachandran VS, Misra D, et al. Hand osteoarthritis in relation to mortality and incidence of cardiovascular disease: data from the Framingham heart study. Ann Rheum Dis 2015;74:74-81.

12. Holsgaard-Larsen A, Roos EM. Objectively measured physical activity in patients with end stage knee or hip osteoarthritis. Eur $J$ Phys Rehabil Med 2012;48:577-85.

13. Suri P, Morgenroth DC, Hunter DJ. Epidemiology of osteoarthritis and associated comorbidities. Pm R 2012;4(5 Suppl):S10-9.

14. Gross A, Kay TM, Paquin JP, et al. Exercises for mechanical neck disorders. Cochrane Database Syst Rev 2015;1:CD004250.

15. Choi BK, Verbeek JH, Tam WW, et al. Exercises for prevention of recurrences of low-back pain. Cochrane Database Syst Rev 2010;1:CD006555.

16. Saragiotto BT, Maher CG, Yamato TP, et al. Motor control exercise for chronic non-specific low-back pain. Cochrane Database Syst Rev 2016;1:CD012004.

17. Dionne CE, Dunn KM, Croft PR, et al. A consensus approach toward the standardization of back pain definitions for use in prevalence studies. Spine 2008;33:95-103.

18. Powers CM. The influence of abnormal hip mechanics on knee injury: a biomechanical perspective. J Orthop Sports Phys The 2010;40:42-51.

19. Burnet EN, Pidcoe PE. Isometric gluteus medius muscle torque and frontal plane pelvic motion during running. J Sports Sci Med 2009;8:284-8.

20. Alpayci M, Şenköy E, Delen V, et al. Decreased neck muscle strength in patients with the loss of cervical lordosis. Clin Biomech 2016;33:98-102.

21. Cholewicki J, Panjabi MM, Khachatryan A. Stabilizing function of trunk flexor-extensor muscles around a neutral spine posture. Spine 1997;22:2207-12.

22. Thigpen CA, Padua DA, Michener LA, et al. Head and shoulder posture affect scapular mechanics and muscle activity in overhead tasks. J Electromyogr Kinesiol 2010;20:701-9.

23. Ostelo RW, Deyo RA, Stratford P, et al. Interpreting change scores for pain and functional status in low back pain: towards international consensus regarding minimal important change. Spine 2008;33:90-4.

24. Suni JH, Miilunpalo SI, Asikainen TM, et al. Safety and feasibility of a health-related fitness test battery for adults. Phys Ther 1998;78:134-48.
25. Vähä-Ypyä H, Vasankari T, Husu P, et al. A universal, accurate intensity-based classification of different physical activities using raw data of accelerometer. Clin Physiol Funct Imaging 2015;35:64-70.

26. Vähä-Ypyä H, Vasankari T, Husu P, et al. Validation of Cut-Points for evaluating the intensity of physical activity with AccelerometryBased mean Amplitude deviation (MAD). PLoS One 2015;10:e0134813.

27. Sievänen $H$, Vähä-Ypyä $H$, Husu $P$, et al. A universal method for accurate classification of physical activity and sedentary behavior with triaxial accelerometry. Med Sci Sports Exerc 2014;46(5S:566-8.

28. Donner A, Klar N. Statistical considerations in the design and analysis of community intervention trials. J Clin Epidemiol 1996;49:435-9.

29. Team RC. R: A language and environment for statistical computing. Ed. Austria: R Foundation for Statistical Computing V, 2014.

30. Office of Disease Prevention and Health Promotion. Physical Activity Guidelines for Americans: US Department of Health and Human Services, 20082008. Available from. https://health.gov/paguidelines/ guidelines/adults.aspx. (accessed 4 April 2017).

31. Aalto A-M, Aro AR, Teperi J et al. RAND-36 as a measure of healthrelated quality of life. reliability, construct validity and reference values in the finnish general population. RAND-36 terveyteen liittyvän elämänlaadun mittarina. Mittarin luotettavuus ja suomalaiset väestöarvot.]. Tutkimuksia 1999;101:49-51.

32. Woodhouse A, Pape K, Romundstad PR, et al. Health care contact following a new incident neck or low back pain episode in the general population; the HUNT study. BMC Health Serv Res 2016;16:81.

33. Suni $\mathrm{JH}$, Taanila $\mathrm{H}$, Mattila VM, et al. Neuromuscular exercise and counseling decrease absenteeism due to low back pain in young conscripts: a randomized, population-based primary prevention study. Spine 2013;38:375-84

34. Myer GD, Kushner AM, Brent JL, et al. The back squat: a proposed assessment of functional deficits and technical factors that limit performance. Strength Cond J 2014;36:4-27.

35. McGill S, Juker D, Kropf P. Quantitative intramuscular myoelectric activity of quadratus lumborum during a wide variety of tasks. Clin Biomech 1996;11:170-2.

36. Kavcic N, Grenier S, McGill SM. Quantifying tissue loads and spine stability while performing commonly prescribed low back stabilization exercises. Spine 2004;29:2319-29.

37. Stevens VK, Vleeming A, Bouche KG, et al. Electromyographic activity of trunk and hip muscles during stabilization exercises in four-point kneeling in healthy volunteers. Eur Spine $J$ 2007;16:711-8.

38. Ketola R, Toivonen R, Häkkänen $\mathrm{M}$, et al. Effects of ergonomic intervention in work with video display units. Scand J Work Environ Health 2002;28:18-24.

39. Waddell G, Newton M, Henderson I, et al. A Fear-Avoidance Beliefs Questionnaire (FABQ) and the role of fear-avoidance beliefs in chronic low back pain and disability. Pain 1993;52:157-68.

40. Ware JE, Sherbourne CD. The MOS 36-item short-form health survey (SF-36). I. Conceptual framework and item selection. Med Care 1992;30:473-83.

41. IImarinen J. Work ability-a comprehensive concept for occupational health research and prevention. Scand J Work Environ Health 2009;35:1-5.

42. Suni JH, Oja P, Laukkanen RT, et al. Health-related fitness test battery for adults: aspects of reliability. Arch Phys Med Rehabil 1996;77:399-405.

43. ATS Committee on Proficiency Standards for clinical pulmonary function Laboratories. ATS statement: guidelines for the six-minute walk test. Am J Respir Crit Care Med 2002;166:111-7.

44. US Department of Health \& Human Services. Physical activity guidelines for Americans. Washington (DC: US Department of Health \& Human Services, 2008. http://www.health.gov/paguidelines/ (accessed 4 Apr 2017). 